\title{
The Impact of Cost Reduction on Price Matching Strategy in the Presence of Hybrid Consumers
}

\author{
Xinlan Ye1, Zhenzhong Guan ${ }^{1 *}$, Miao Ouyang² \\ ${ }^{1}$ School of Economics and Management, Southwest Jiaotong University, Chengdu, China \\ ${ }^{2}$ School of Mathematics, Southwest Jiaotong University, Chengdu, China \\ Email: yexinlan@my.swjtu.edu.cn, `zzguan@swjtu.cn, mouyang@xmut.edu.cn
}

How to cite this paper: Ye, X.L., Guan, Z.Z. and Ouyang, M. (2020) The Impact of Cost Reduction on Price Matching Strategy in the Presence of Hybrid Consumers. Journal of Mathematical Finance, 10, 77-95. https://doi.org/10.4236/jmf.2020.101007

Received: December 29, 2019

Accepted: January 19, 2020

Published: January 22, 2020

Copyright (๑) 2020 by author(s) and Scientific Research Publishing Inc. This work is licensed under the Creative Commons Attribution International License (CC BY 4.0).

http://creativecommons.org/licenses/by/4.0/

\section{(c) (i) Open Access}

\begin{abstract}
This article mainly considers the impact of cost reduction on price matching strategy when a firm sells products in two periods. The cost reduction in the second period is due to technological advancement and production learning. The market is made up of myopic consumers and strategic consumers. The conclusions show that firm's optimal profit will decrease with the increase of the fraction of strategic consumers. Besides, when the production learning effect dominates, the firm sells at a reduced price in two periods. When the technological advancement effect dominates, the firm maintains a uniform price for sale throughout the sales period. Finally, both the technological advancement and production learning effect can effectively reduce the loss of profits caused by strategic consumers, and the effect of the technological advancement is more significant.
\end{abstract}

\section{Keywords}

Strategic Consumer, Price Matching, Cost Reduction, Technological Advancement, Production Learning

\section{Introduction}

Due to the continuous development of electronic information technology, electronic products are updated quickly. And there is a strong scale effect in the production process of electronic industry products, resulting in the cost of electronic products will decline in the sales process. In December 2018, Huawei engineers upgraded SCP (Super Charge) fast charging technology, retaining the black technology - charge pump technology, which is expected to significantly reduce handset costs. In addition, mobile phones such as Samsung and Xiaomi also experience this phenomenon throughout the sales process. The innovation 
of production process has greatly reduced the cost of raw materials, machine consumption cost and production cost of the firm in the production process. This cost reduction is independent of production volume. Shum et al. [1] called it technological advancement effect. On the other hand, what's more common is in the continuous production and processing engineering, the production workers gradually become familiar with the production and processing routes of the products, which will improve the production efficiency, and help to improve the production process, saving time and cost. This effect of reducing costs requires continuous learning. Only when the production volume reaches a certain level can it play a very good role. Shum et al. [1] call it the production learning effect. Alchian [2] and Benkard [3] have studied the application of the production learning effect in the spacecraft field, all of which indicate that production learning contributes to lower production costs. These two cost reduction effects are very common in production activities. But in addition to the two effects, consumers' behaviors also have an impact on the pricing of the product. There exists a type of consumers who always wait until the price of the commodity is reduced. In the study, such consumers are often referred to strategic consumers (or forward-looking consumers), and Guan and Ren [4] indicate the existence of strategic consumers has greatly damaged the interests of manufacturers. With the development of the Internet and information technology, it is more and more convenient for strategic consumers to obtain information. The struggle between strategic consumer and retailer is becoming fiercer. It is very important to formulate strategies to effectively prevent or eliminate the waiting behavior of strategic consumers.

Our paper studies the price matching strategy when both strategic consumers and myopic consumers are present in the market, considering the fraction of strategic consumers and the cost reduction which is due to the technological advancement and production learning effect in period 2. Our results show that when there are few strategic consumers in the market, firms tend to ignore consumers with low reservation value, which leads to the prices of the product being closer in both periods. The similar prices in the two periods can also reduce the extra expenditure of the firm in the second period due to price matching. Our second major result is that when the production cost of the two periods remain unchanged, the product will be sold in two periods at different price, and when the cost of the period 2 decreases, the firm will have two situations, when the production learning effect dominates (or the technological advancement effect is weak), the firm will sell products in two periods and offer markdown in the second period. When the technological advancement effect dominates (or the production learning effect is weak), the product is only sold during period 2, or in other words, the price of the product will not change during the selling period. Our results also indicate that when the firm offers markdown in the second period, if the firm's technological advancement effect is more obvious, the firm can make decision through the price combination of high price in period 1 and low price (significantly lower than period 1 pricing) in period 2 to maximize its 
profits. For the firm, which is more obvious in production learning effect, can maximize the firm profit by the price combination of the low price in period 1 and the high price (slightly lower than the period 1 price) in period 2. In addition, among the two factors which affecting the production cost discussed in this paper, the technological advancement effect has a more significant impact on the firm profit.

The rest of the paper is organized as follows: In Section 2, we review the relevant literature. We then describe the model, and propose some hypotheses in Section 3. In Section 4, we build the model and develop the optimal solutions. We compare and analyze the results obtained by the model in Section 5. Finally, Section 6 including managerial insights and conclusion.

\section{Literature Review}

\subsection{Strategic Consumers}

In the research of strategic consumers, $\mathrm{Su}$ [5] first introduced strategic behavior into the firm in pricing operation decision, and studied a dynamic pricing model with endogenous intertemporal demand. The paper proves that valuation and patience heterogeneity are important because they determine the structure of the optimal pricing policy together. The paper also reveals how the composition of the customer base affects the best income, consumer surplus and social welfare. Since then, more and more scholars and the firm managers have found that the impact of consumer behavior on the firm is very important and has carried out a series of studies.

In a large number of literature studies, we found that there are two main ways to deal with strategic consumers. The first is to limit inventory and create outof-stock risks. Liu and van Ryzin [6] studied the market for both strategic consumers and myopic consumers, and how the firm deliberately created out-ofstock risks through a limited rationing strategy, thereby inducing strategic consumers to purchase early. In terms of inventory, there are many scholars who study the impact of QR (quick response) on eliminating consumer behavior. For example, Yin et al. [7] show that incomplete inventory information can help mitigate the adverse effects of strategic consumer behavior. Chen et al. [8] studied the value of the firm's differential quality design and rapid response when there is a certain fraction of strategic consumers. Wang et al. [9] retailers sell products to strategic consumers with risk appetite and lower valuations, and make pricing and order quantity decisions. When QR costs are low, QR strategy can mitigate the behavior of strategic consumers and Retailers bring profits. In addition, the implementation of the pre-sale strategy can also be purchased in advance by consumers, and help the firm to reduce the losses caused by inventory backlog. Osadchiy and Vulcano [10], Wei and Zhang [11] studied the firm's decision to make a binding reservation, that is, during the sales period, consumers must decide to purchase at full price or make an irrevocable reservation at a discounted price. And after the end of the sales period, it is allocated on a first come, first 
served basis. And the firm through the PCP (the Preorder Contingent Production) strategy to make production decisions based on pre-sale targets, can effectively reduce the strategic waiting behavior, thereby significantly improving the firm's profits.

The second way is to increase the consumer's willingness to purchase, such as directly increasing the customer's willingness to pay so as to increase the expected surplus of their immediate purchase, such as Benetton, it improves the customer's willingness to pay by improving the clothing design. This method is the most direct and effective. In addition, choosing the right pricing strategy can also reduce or even eliminate the strategic behavior of strategic consumers to some extent. Su and Zhang [12] studied the limited availability (quantity commitment) or the price will remain high (price commitment) to prove that the seller's profit can be improved. Özer and Zheng [13] have shown that when there is a certain fraction of strategic consumers in the market, Özer and Zheng [13] indicated that when there is a certain percentage of strategic consumers in the market, the firm will choose between every-low-price and markdown strategies, and thus make price and inventory decisions. In addition, Consumer behavior is affected by their misunderstanding about the availability of the product and regret. Shum et al. [1] studied the impact of dynamic pricing, price commitment and price matching on the firm profit when the firm's production cost is reduction and uncertain. The conclusion is that the price matching strategy can eliminate the consumer's strategic behavior. More research on price matching strategies will be presented in Section 2.2.

\subsection{Price Matching Strategy}

When it comes to the firm's pricing decision, price matching is usually the most effective choose. If the firm cuts the price during the second sales period, consumers will be able to make up for the loss that caused by asking for compensation. This approach eliminates the strategic wait in strategic consumers. Chen et al. [14] show that price matching not only produces competitive inhibition effects, but also produces competitive promotion effects. Lai et al. [15] studied the pricing strategy for strategic consumers in the price exogenous, and proposed that the PM (price matching) policy can eliminate the waiting incentives of strategic consumers, allowing the firm to raise prices during the regular sales season. Especially when the fraction of strategic consumers is not too small and their valuations are not too low or too high over time, PM policies can greatly increase the firm's profits, as well as inventory investment. Peng et al. [16] considered the choice between the firm's dynamic pricing and price matching strategies when there were strategic consumers. Dutta et al. [17] studied the impact of refunds on consumer prices after high-priced purchases, and concluded that the impact of refunds on regrets depends on how consumers perceive these commitments. When consumers primarily view it as a protection tool, late refunds are rarely regrettable. Xing and Liu [18] also studied the impact of price matching strategies and selective compensation on supply chain coordination in the presence of 
free-riding effects.

\subsection{The Change of Production Cost}

The cost of a product during the production and sale of a product is often not static. Recently, there are also literatures that focus on the relationship between product pricing and product cost. For example, Tang and Zheng [19] construct a game model of the firm and consumers in the case of cost public and private information, and analyze cost information. Disclosure affects consumer buying behavior, which in turn affects the firm's pricing strategy and profits. However, the paper does not consider the change in the cost of the firm during the sales period. A large body of literature indicates that the cost of the firm will change during the production process, the most common being the cost reduction due to the production learning effect. In 1936, Dr. TPW right of Cornell University in the United States first discovered and proposed the concept of learning curve through observation, analysis and research on a large number of relevant materials and cases. Later, Arrow [20] carried out the effect of production learning, their research involves the empirical relationship between market size and output, but has not been well explained. It was not until the introduction of the new growth theory that it slowly caught people's attention, but these studies ignored the demand side. Hiller and Shapiro [21] used mathematical programming models to analyze the firm's capacity expansion plan in the face of important learning effects in production and markets. Hatch and Mowery [22], Cabral and Leiblein [23] focused on the semiconductor industry the relationship between production learning effect and process innovation, and the conclusion that manufacturing yield is a catalyst for cost reduction. Alchian [2] and Benkard [3] both analyzed the application of the production learning effect in the spacecraft field. All three indicate that production learning contributes to lower production costs. Other scholars such as Kalish [24], Cabral and Leiblein [23], and Riordan [25] also considered the impact of production learning in the firm product price decision.

Different from these papers, firstly, this paper considers the existence of strategic consumers and myopic consumers in the market, and considers that the strategic behavior of consumers will not only affect the pricing level of the firm, but also the cost per unit of product. Secondly, we consider two factors that influence the cost of the firm in period 2 in the model, which are production learning effect and technological advancement effect, and explain the changes of the firm's decision of when either of the two effects dominate. Finally, we enriches the background of the implementation of the price matching strategy and discusses the impact of implementing the price matching strategy on the firm price level and profit based on the cost reduction in period 2.

\section{Model}

\subsection{Abbreviations and Acronyms}

A monopoly firm sells a product at a price reduction in two periods. During the 
sales period, the product supply is sufficient. Without loss of generality, the product has a residual value of zero at the end of the entire sales period. The price of the product is $p_{i}\left(p_{2}<p_{1}\right)$ in $i(i=1,2)$ period. And the production cost of the firm period 1 is $c(c<1)$. However, due to the firm's advancement and production learning effects in the production process, the production cost of period 2 is usually reduced. This paper considers the situation that the firm advancement and production learning lead to reduction of the firm cost, in which the strength of the technological advancement effect is expressed by $\alpha$, and the strength of the production learning effect is represented by $\beta$. Under the effects of these two factors, the unit production cost of period 2 can be expressed as $c_{2}$, where $c_{2}=c-\left(\alpha+\beta q_{1}\right), \quad q_{1}$ represents the total sales of the firm in period 1 . To ensure the firm's production cost and the two factors are non-negative, we assume that both $\alpha$ and $\beta$ are positive and $\alpha+\beta<c$. In addition, the reduction in actual cost is only achieved at the beginning of period 2 and the production cost is private information of the firm.

In order to effectively slow down or eliminate the consumer's strategic behavior, this paper considers that the firm adopts dynamic pricing in two periods, that is, the firm only announces the price of the product at the beginning of each period. In addition, in order to induce strategic consumers to make purchases earlier, the firm adopts price matching at the beginning of period 1, that is, the firm promised that if the product was reduced in price 2, then the firm would fully compensate consumers who purchased the product in period 1. Take Gome and Suning as an example. When the consumer purchases the product, if the product is reduced in the specified time, the consumer can ask for the full difference. This system can effectively eliminate the burden of consumer claims. However, when the price of the product drops, the mall will not actively inform the consumers who buy at high prices, so only when the consumers themselves observe the price goes down can they ask for price matching. Therefore, according to the definition of myopic consumers and strategic consumers, in this paper we assume that among the consumers purchased by period 1, myopic consumers leave the market directly after purchasing the products. The strategic consumers will wait until the next sales period to confirm whether compensation can be obtained.

This paper considers a market with a certain size, the market size is $N$, without loss of generality, we assume $N=1$. There are both myopic consumers and strategic consumers on the market. In the decision-making, strategic consumers will not only consider the utility of the current purchase, but also compare the utility of the purchase in period 2, and finally decide which period to buy, the proportion of such consumers is $\theta$. The proportion of myopic consumers is $1-\theta$, they only decide whether to buy according to the utility of the current purchase. The consumer is heterogeneous, and the consumer's valuation of the product is subject to a distribution of $[0,1]$, which is the common knowledge of the firm and the customer. It should be noted that the utility of the consumer's purchase of the product will change over time, and the utility obtained in the 
purchase of the period 2 will be discounted by a constant $\delta$, where $0<\delta<1$. In this article, due to the existence of price matching, the utility of the strategic consumers who evaluate the product as $v$ is the $U_{1}^{S}=v-p_{1}+\delta\left(p_{1}-p_{2}\right)$ in the purchase of one unit of product in period 1 , and the utility of purchasing in period 2 is $U_{2}^{S}=\delta\left(v-p_{2}\right)$, This similar expression of the consumer utility function can be found in [1] [4] [6] [12] [26]. We use the superscript $S$ and $M$ to signify strategic consumers and myopic consumers respectively. So when $U_{1}^{S} \geq 0$ and $U_{1}^{S} \geq U_{2}^{S}$, the strategic consumers choose to buy in period 1 , otherwise they will wait until period 2 . In the process, there are indistinguishable strategic consumers, so that let $U_{1}^{S}=U_{2}^{S}$, we get indistinguishable strategic consumers to evaluate the product as $\bar{v}=p_{1}$. Without loss of generality, we assume that there is no difference between strategic consumers purchasing products in period 1. For myopic consumers, the condition they bought in period 1 is $U_{1}^{M}=v-p_{1} \geq 0$. In period 2, both myopic consumers and strategic consumers only consider the utility of the current purchase, and choose to buy immediately if and only if $\delta\left(v-p_{2}\right) \geq 0$, otherwise exit the market. Throughout the game, the consumer's goal is to maximize consumer surplus, and the firm goal is to maximize profits. Figure 1 illustrates the game sequence.

Period 1: The firm announced the sales price $p_{1}$ in period 1, and announced the adoption of a price matching strategy. When consumers reach the market, strategic consumers compare the potential benefits of purchases in period 2 and decide whether to buy them now. Myopic consumers make decisions based on their own valuation of the product and the price of period 1.

Period 2: The firm announced the price $p_{2}$ in the period 2. and the customers who did not purchase in period 1 (including both strategic consumers and myopic consumers) made their decision based on their own valuation of the product and the price in period 2, and the strategic consumers purchased at period 1 ask for compensation from the firm.

\subsection{Basic Model}

In order to better examine the situation when the cost is reduced, we will consider a basic model (indicated by the superscript $b$ ) in this section. This model

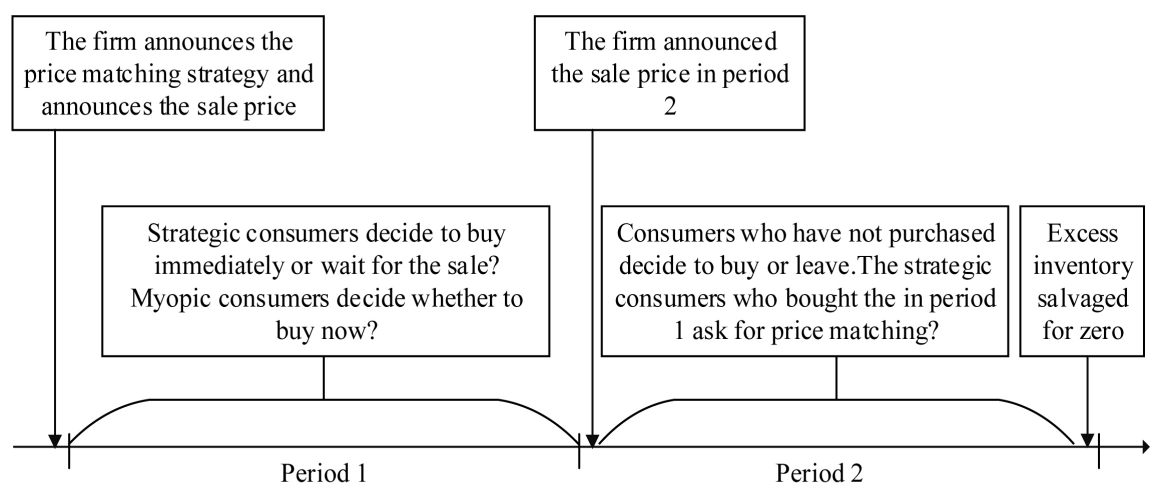

Figure 1. Sequence of events of the firm and consumer. 
discusses the constant unit cost of the period 2 product $c_{2}=c$. Table 1 summarizes the consumer's demand for two sales periods in the basic model, where $d$ represents demand, subscripts 1 and 2 represent sales periods, and superscripts indicate consumer types.

We use the inverse derivation method to solve the model (superscript ${ }^{*}$ indicates the optimal solution).

The firm's profit in period 2 is

$$
\pi_{2}=\left(p_{2}-c_{2}\right) d_{2}-\left(p_{1}-p_{2}\right) d_{1}^{S}
$$

where $\bar{v}=p_{1}$.

We derive the profit function of period 2, let $\partial \pi_{2} / \partial p_{2}=0$, and obtained the optimal pricing for the firm period 2:

$$
p_{2}=\left(c+\theta+p_{1}-\theta p_{1}\right) / 2
$$

The total profit of the two periods is:

$$
\pi=\left(p_{1}-c\right) d_{1}+\pi_{2}
$$

Proposition 1 summaries the optimal pricing, sales and total profit of the firm in two periods when the cost is constant during the two periods, and analyzes how the patience level of strategic consumers and the fraction of strategic consumers affects the above variables.

Proposition 1. When the cost of the two periods is constant, the firm's optimal price for the two periods are $p_{1}^{b^{*}}=(2+c+\theta) /(3+\theta)$,

$p_{2}^{b^{*}}=(1+2 c+\theta) /(3+\theta)$, sales are $q_{1}^{b^{*}}=q_{2}^{b^{*}}=(1-c) /(3+\theta)$, and the optimal total profit is $\pi^{b^{*}}=(1-c)^{2} /(3+\theta)$. Specifically.

1) $p_{1}^{b^{*}}, p_{2}^{b^{*}}, q_{1}^{b^{*}}, q_{2}^{b^{*}}$ and $\pi^{b^{*}}$ are independent of $\delta$.

2) When $\theta$ increases, $p_{1}^{b^{*}}, p_{2}^{b^{*}}$ increases, $q_{1}^{b^{*}}, q_{2}^{b^{*}}$ and $\pi^{b^{*}}$ decreases.

Proposition 1 shows that when the cost of two periods is constant, the price of the product increases as the fraction of strategic consumers increases, and the total profit of the firm decreases as the fraction of strategic consumers increases. Considering the implementation of the price matching strategy, consumers who have a reservation price greater than $p_{1}$ in period 1 will be purchased and will not be affected by the price of period 2 . So, the firm will increase the price of period 1 to increase the profit of period 1 . At the same time, in order to reduce the loss of profits due to price matching strategy, the firm will also increase the price of period 2 to minimize the price difference $p_{1}-p_{2}$. However, due to the

Table 1. Consumer demand in two periods.

\begin{tabular}{cccc}
\hline \multirow{3}{*}{ Sales period } & \multicolumn{3}{c}{ Consumer demand } \\
\cline { 2 - 4 } & Strategy customers & Myopic consumers & Total demand \\
\hline Period 1 & $d_{1}^{S}=\theta(1-\bar{v})$ & $d_{1}^{M}=(1-\theta)\left(1-p_{1}\right)$ & $d_{1}=1-p_{1}$ \\
Period 2 & $d_{2}^{S}=\theta\left(\bar{v}-p_{2}\right)$ & $d_{2}^{M}=(1-\theta)\left(p_{1}-p_{2}\right)$ & $d_{2}=p_{1}-p_{2}$ \\
\hline
\end{tabular}


increase in the price of the firm two periods, and the customer's reservation price for the product is certain, the consumer who purchases the product with a lower reservation price may obtain utility less than zero. As a result, the sales of the two periods decreased with the increase of the fraction of strategic consumers, causing the firm to lose some consumers. Therefore, when the fraction of strategic consumers is higher, the firm profit will be reduced by the loss of many undervalued customers.

\subsection{Equilibrium Analysis of Cost Reduction}

Due to the existence of technological advancement and production learning effects, the cost in period 2 products tends to decrease. Proposition 2 summarizes the pricing decisions and profits of firm when the cost in period 2 decreases. The specific solution method is the same as the cost determination. $p_{1}^{D^{*}}$ and $p_{2}^{D^{*}}$ represents the optimal pricing combination, $q_{1}^{D^{*}}$ and $q_{2}^{D^{*}}$ represents the twostage sales, and $\pi^{D^{*}}$ represents the total profit of firm during the sales period.

Proposition 2. When cost reduction happens, the firm has two situations for the sale of the product, the optimal prices, expected sales and optimal profit are as follows.

1) When $\alpha /(1-c)<(1-\theta+\beta) /(1-\beta+\theta)$,

$$
\begin{gathered}
p_{1}^{D^{*}}=\frac{2 \alpha-(\beta-\theta)^{2}+(\beta-\theta+1)(1-\alpha+c)+1}{(3-\beta+\theta)(\beta-\theta+1)}, \quad p_{2}^{D^{*}}=\frac{1-\alpha-\beta+2 c+\theta}{3-\beta+\theta}, \\
q_{1}^{D^{*}}=\frac{\alpha(\beta-\theta-1)+(1-c)(\beta-\theta+1)}{(3-\beta+\theta)(\beta-\theta+1)}, q_{2}^{D^{*}}=\frac{2 \alpha+(1-c)(\beta-\theta+1)}{(3-\beta+\theta)(\beta-\theta+1)}, \\
\pi^{D^{*}}=\frac{\alpha^{2}+(1-c)(\beta-\theta+1)(1-c+\alpha)}{(\beta-\theta+1)(3-\beta+\theta)} .
\end{gathered}
$$

2) When $\alpha /(1-c)>(1-\theta+\beta) /(1-\beta+\theta)$,

$$
p_{1}^{D^{*}}=p_{2}^{D^{*}}=\frac{1}{2}(1+c-\alpha), \quad q_{1}^{D^{*}}=q_{2}^{D^{*}}=\frac{1}{2}(1-c+\alpha), \pi^{D^{*}}=\frac{1}{4}(1-c+\alpha)^{2} .
$$

Proposition 2 shows that when $\alpha /(1-c)<(1-\theta+\beta) /(1-\beta+\theta)$, the production learning effect dominates, firm needs to accumulate a certain amount of sales in period 1 to ensure that the production learning effect can fully play its role, thus greatly reducing the cost of period 2 . So firm must be sold in the segment market. When $\alpha /(1-c)>(1-\theta+\beta) /(1-\beta+\theta)$, the technological advancement dominants, and the technological advancement can reduce production costs without being affected by other factors. Figure 2 indicates how the sales period changed for the firm (where $\beta=0.15$ ) in the case of cost reduction. When there are more strategic consumers in the market, the price of the two-stage sales of the firm is equal. In other words, the firm sells in a non-segment market.

In both cases, how does the proportion of strategic consumers and strategic consumer patience affect retailers' prices, sales, and total profits? The following proposition gives an analysis. 


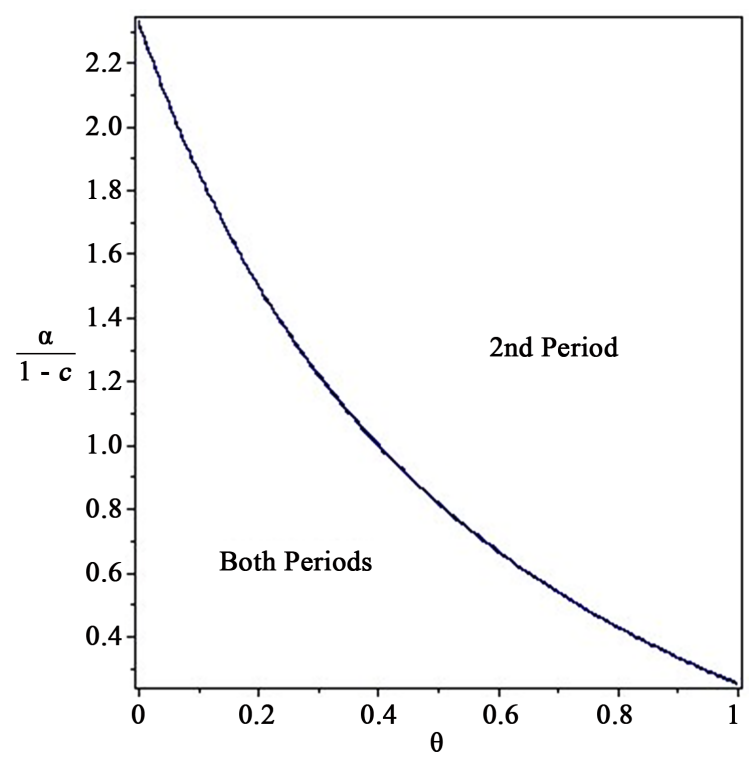

Figure 2. Distribution of sales period under cost reduction.

Proposition 3. The impact of $\delta$ and $\theta$ :

1) When $\alpha /(1-c)<(1-\theta+\beta) /(1-\beta+\theta), \quad p_{1}^{D^{*}}, \quad p_{2}^{D^{*}}, \quad q_{1}^{D^{*}}, \quad q_{2}^{D^{*}}$ and $\pi^{D^{*}}$ are independent with $\delta . p_{1}^{D^{*}}$ and $p_{2}^{D^{*}}$ are positively related to $\theta . q_{1}^{D^{*}}$ and $q_{2}^{D^{*}}$ are negatively related to $\theta . \pi^{D^{*}}$ is negatively related to $\theta$.

2) When $\alpha /(1-c)>(1-\theta+\beta) /(1-\beta+\theta), \quad p_{1}^{D^{*}}, \quad p_{2}^{D^{*}}, q_{1}^{D^{*}}, q_{2}^{D^{*}}$ and $\pi^{D^{*}}$ are independent with $\delta$ and $\theta$.

According to Proposition 3, since the firm adopts a price matching strategy, the strategic waiting behavior of strategic consumers is eliminated to some extent. Therefore, the firm's optimal price and total profit are independent of the patient's patience. When the production learning effect dominates (i.e., $\alpha /(1-c)<(1-\theta+\beta) /(1-\beta+\theta))$, the optimal price of both periods increases as the proportion of strategic consumers increases. This is because that regardless of the price of the product, as long as the price of period declines, the strategic consumers who purchase in the period 1 can get compensation. So when the proportion of strategic consumers in the market increases, the firm will set a higher first-period price. In addition, in order to reduce the loss caused by the firm in the period 2 due to the compensation difference, the price of the period 2 product will also increase with the proportion of strategic consumers. However, the increase in the two-period price is very unfavorable for short-sighted consumers, and the increase in the price of the period 2 will also cause the firm to lose some of the strategic consumers with lower prices. As a result, two-period sales and total profit will decrease as the proportion of strategic consumers increases. When the technological advancement effect dominates (i.e., $\alpha /(1-c)>(1-\theta+\beta) /(1-\beta+\theta))$, the firm sells in a non-segment market. If the consumer does not purchase at this period, it will exit the market, so the firm's best price, sales volume and total profit are both strategic consumption. The proportion of the person has nothing to do with the patient's patience. 
Proposition 4. The impact of $\alpha$ and $\beta$ :

1) When $\alpha$ increases, $p_{2}^{D^{*}}$ may decrease, $p_{1}^{D^{*}}$ and $\pi^{D^{*}}$ may increase if the production learning effect dominants (i.e., $\alpha /(1-c)<(1-\theta+\beta) /(1-\beta+\theta)$ ). If the technological advancement effect dominants (i.e.,

$\alpha /(1-c)>(1-\theta+\beta) /(1-\beta+\theta)), \quad p_{1}^{D^{*}}$ and $p_{2}^{D^{*}}$ may decrease, and $\pi^{D^{*}}$ increases.

2) When $\beta$ increases, $p_{1}^{D^{*}}$ and $p_{2}^{D^{*}}$ may decrease, $\pi^{D^{*}}$ may increase if the production learning effect dominants (i.e., $\alpha /(1-c)<(1-\theta+\beta) /(1-\beta+\theta)$ ). If the technological advancement effect dominants (i.e., $\alpha /(1-c)>(1-\theta+\beta) /(1-\beta+\theta)), p_{1}^{D^{*}}, \quad p_{2}^{D^{*}}$ and $\pi^{D^{*}}$ are independent with $\beta$.

Proposition 4 indicates that when the firm's the production learning effect dominates, the two periods price increases as the production learning effect beta increases. When the firm has a strong production learning effect, in order to ensure that the production learning effect fully plays its role, firms tend to set a lower price in period 1 to attract consumers to buy in advance, and in this way to improve production learning. In period 2, due to lower production costs, the firm does not have to set a high price to gain profit from each product. In general, when the production learning effect dominates, firms will adopt a sales approach of small profits and quick returns, profiting from large amounts of sales, making total profits increase as the production learning effect increases. In addition, when the production learning effect dominates, the price of period 1 increases as the technological advancement effect increases, and the price of period 2 decreases as the technological advancement effect increases. Since the technological advancement effect is not subject to production constraints, it tends to have a more significant effect on firms. When the technological advancement effect is gradually enhanced, the firm can set a higher price of period 1 and benefit from high-retention consumers. When period 2 is cost-effective due to technological advances, consumers with low retention value are retained at low prices. But overall, for a business that is dominated by the production learning effect, the high price of period 1 is often unfavorable for firms, so the total profit of firms will decrease as the technological advancement effect increases.

When the technological advancement effect dominates, the firm sells in a non-segment market. In other words, the product is priced uniformly throughout the sales period. The price of the product is only related to the technological advancement effect and is not affected by the production learning effect. When the technological advancement effect is stronger, the production cost of the product is lower and the product price is lower. Eventually, product sales increased significantly, and the total profit of the firms increased with the increase of the technological advancement effect.

\section{Comparative Analysis}

This section analyzes the impact of the fraction of strategic consumers $\theta$, the 
technological advancement effect $\alpha$, and the production learning effect $\beta$ on firm pricing levels and profits. We use $r$ represents the ratio between firm period 2 and period 1 price, also known as price discount of the product, $r=p_{2} / p_{1}$. Use the value of the firm that represents firm. Equation (4) and Equation (5) give the expression $r$ and $\Delta \pi$.

$$
\begin{gathered}
r= \begin{cases}\frac{2 c+\theta+1}{c+\theta+2} & \text { for } c=c_{2} \\
\frac{(\beta-\theta+1)(1-\alpha-\beta+2 c+\theta)}{2 \alpha-(\beta-\theta)^{2}+(\beta-\theta+1)(1-\alpha+c)+1} & \text { for } c>c_{2} \\
1 & \text { and } \frac{\alpha}{1-c}<\frac{1-\theta+\beta}{1-\beta+\theta}(4)\end{cases} \\
\Delta \pi= \begin{cases}\frac{-\alpha^{2}(\theta+3)+\alpha(1-c)(\theta+3)(\beta-\theta+1)-\beta(1-c)^{2}(\beta-\theta+1)}{(\theta+3)(\theta-\beta-1)(3-\beta+\theta)} & \text { for } \frac{\alpha}{1-c}<\frac{1-\theta+\beta}{1-\beta+\theta} \\
\frac{1}{4}(1-c+\alpha)^{2}-\frac{(1-c)^{2}}{\theta+3} & \text { and } \frac{\alpha}{1-c}>\frac{1-\theta+\beta}{1-\beta+\theta}\end{cases} \\
\end{gathered}
$$

\subsection{The Impacts of $\theta$ on $r$ and $\Delta \pi$}

Here, we compare the effect of the fraction of strategic consumers on the price discount of the product when the cost is constant and the cost is reduced (the cost reduction is caused by the technological advancement utility and the production learning effect). Proposition 5 was obtained by analysis and calculation.

Proposition 5. When the cost is constant, the price discount $r$ is positively correlated with $\theta$. When the cost is reduced, there are two situations:

1) When $\alpha /(1-c)<(1-\theta+\beta) /(1-\beta+\theta), r$ increases firstly and then decreases on $\theta$.

2) When $\alpha /(1-c)>(1-\theta+\beta) /(1-\beta+\theta), r$ is independent of $\theta$, and $r=1$.

Proposition 5 shows that when the two-stage cost is constant, in order to obtain greater profit when firm implements the price matching strategy, firms tends to set a higher price in period 1 to earn revenue from customers with high reservation price (Figure $3(\mathrm{a})$ ), but with the increase of the fraction of strategic consumers, there will be a large number of consumer ask for price matching in period 2, and compensation will be obtained. If the price difference between the two stages is large at this time, it will cause great loss to firm. Therefore, firm will increase the price of the product at period 2, resulting in an increase with the increase in the fraction of strategic consumers. Figure $3(\mathrm{~b})$ depicts the case of a decrease in the cost of period 2 (where $\alpha=0.18, \beta=0.18, c=0.4$ ). The firm's price in period 2 is at a lower level due to a decrease in the production cost of the firm in period 2. In addition, it can be found that when the fraction of strategic consumers in $\theta \in(0,0.718)$, the firm the production learning effect dominates. Firm sells at periodic 2 at a price cut. And when $\theta \in(0,0.390)$, the price discount $r$ increases as the fraction of strategic consumers increases, when $\theta \in(0.390,0.718), r$ decreases as the fraction of strategic consumers increases. 


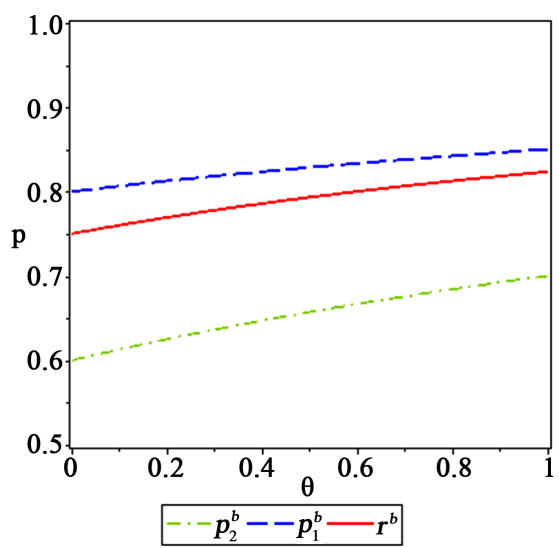

(a)

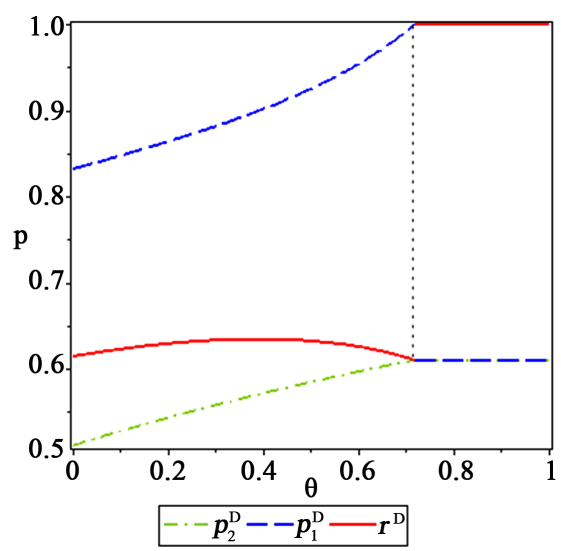

(b)

Figure 3. The impacts of $\theta$ on prices and $r$ at different costs. (a) Cost constant in two periods (b) Cost reduction in period 2.

When $\theta \in(0.718,1)$, when the technological advancement effect is significant, the two-stage price of the firm remains the same, and the price has nothing to do with the fraction of strategic consumers.

On the whole, the fluctuation of the two-stage price after the cost reduction is significantly smaller than the case when the two-stage cost is consistent. The cost reduction caused by the technological advancement and the production learning effect can effectively alleviate the influence of the consumer's strategic behavior on the firm pricing level.

Proposition 6. The impacts of $\theta$ on $\Delta \pi$ : When $\theta$ increases, $\Delta \pi$ may decrease firstly and then increase if the production learning effect dominants (i.e., $\alpha /(1-c)<(1-\theta+\beta) /(1-\beta+\theta))$. If the technological advancement effect dominants (i.e., $\alpha /(1-c)>(1-\theta+\beta) /(1-\beta+\theta)), \pi^{D^{*}}$ increases (i.e., $\partial \Delta \pi / \partial \theta>0)$.

Proposition 6 shows that when the technological advancement effect dominants or the production learning effect is weak, the value of cost reduction increases as the proportion of strategic consumers increases. However, when the technological advancement effect is weak or the production learning effect dominants, the situation becomes extremely complicated. Therefore, we use the example to give the effect of the pair, as shown in Figure 4. We selected four sets of data to analyze the effect of different combinations of $\theta$ and $\theta$ on firm profit. The four groups are the technological advancement and production learning are not significant $\theta$, only the production learning effect is significant $\theta$, only the technological advancement effect is significant $\theta$, the technological advancement and production learning are significant $\theta$, of which the unit cost of the product 1 is $\theta$, the results obtained are shown in Figure 4.

Figure 4 indicates that when the technological advancement and the production learning effect are weak, the effect of the fraction of strategic consumers $\theta$ on the price matching profit change is not obvious. When the technological advancement and the production learning effect are both significant, the firm profit 


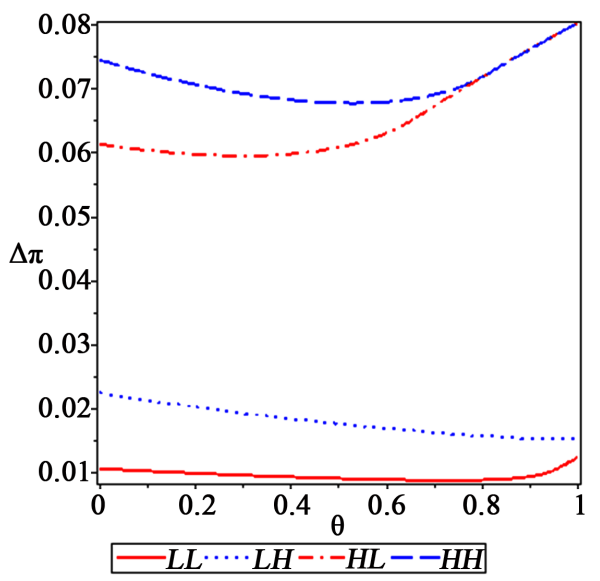

Figure 4. The effect of the fraction of strategic consumers $\theta$ on the value of the cost reduction $\Delta \pi$.

is initially affected by the consumer's strategic behavior and decreases as the fraction of strategic consumer increases. But when the proportion of strategic consumers in the entire market reaches a certain level (Figure 4, when $\theta>0.75$ ), the firm profit increases with the increase of the fraction of strategic consumers. In addition, we also noticed that the change in profit caused by the increase in the production learning effect is significantly less than the change in profits brought by the technological advancement. Therefore, we believe that the effect of the technological advancement effect on the firm profit is significantly stronger than the effect of the firm the production learning effect.

\subsection{The Impacts of $\alpha$ and $\beta$ on $r$ and $\Delta \pi$}

In order to study the effect of the change of the technological advancement effect and the production learning effect on the firm pricing level and profit, we calculate the effect of the value discount on the product by numerical calculation in the interval of $\alpha \in(0.04,0.28)$ and $\beta \in(0.04,0.40)$, as shown in Table 2. In addition, in the interval of $\alpha \in(0.16,0.40)$ and $\beta \in(0.04,0.40)$, the results of the influence of $\alpha$ and $\beta$ to the profit change $\Delta \pi$ before and after the decrease of the cost of the firm period 2 are obtained by numerical calculation, as shown in Table 3. The cost of period 1 and the fraction of strategic consumers are both at a medium level $(c=0.4, \theta=0.5)$.

1) The impacts of $\alpha$ and $\beta$ on $r$

When the technological advancement and the production learning effect are weak, the cost of the firm is not significantly reduced. Firm needs to reduce the gap between $\alpha$ and $\beta$ to reduce the strategic consumers who seek price matching in period 2 due to the high price purchase, bringing a loss of profits. When the technological advancement effect is significant, the price of firm in the two periods remains the same, so the price discount of the product $r=1$. When the production learning effect is significant (as shown in Table 2), the firm is sold in two stages, and the price discount of the product decreases as the technological 
Table 2. The impacts of $\alpha$ and $\beta$ on $r$.

\begin{tabular}{cccccccc}
\hline$\beta$ & \multicolumn{7}{c}{$\alpha$} \\
\cline { 2 - 7 } & 0.04 & 0.08 & 0.12 & 0.16 & 0.2 & 0.24 & 0.28 \\
\hline 0.04 & 0.748 & 0.709 & 0.672 & 0.638 & 0.606 & 0.576 & 0.547 \\
0.08 & 0.747 & 0.710 & 0.674 & 0.641 & 0.610 & 0.581 & 0.553 \\
0.12 & 0.746 & 0.710 & 0.676 & 0.644 & 0.614 & 0.585 & 0.558 \\
0.16 & 0.744 & 0.710 & 0.677 & 0.646 & 0.617 & 0.589 & 0.562 \\
0.2 & 0.743 & 0.709 & 0.677 & 0.647 & 0.619 & 0.591 & 0.565 \\
0.24 & 0.740 & 0.708 & 0.677 & 0.648 & 0.620 & 0.593 & 0.567 \\
0.28 & 0.738 & 0.707 & 0.677 & 0.648 & 0.621 & 0.594 & 0.569 \\
0.32 & 0.736 & 0.705 & 0.676 & 0.648 & 0.621 & 0.595 & 0.570 \\
0.36 & 0.733 & 0.703 & 0.674 & 0.647 & 0.620 & 0.595 & 0.570 \\
0.40 & 0.730 & 0.701 & 0.673 & 0.646 & 0.619 & 0.594 & 0.570 \\
\hline
\end{tabular}

Table 3. The impacts of $\alpha$ and $\beta$ on $\Delta \pi$.

\begin{tabular}{cccccccc}
\hline$\beta$ & & & \multicolumn{5}{c}{$\alpha$} \\
\cline { 2 - 8 } & 0.16 & 0.20 & 0.24 & 0.28 & 0.32 & 0.36 & 0.40 \\
\hline 0.04 & 0.043 & 0.057 & 0.074 & 0.092 & 0.111 & 0.133 & 0.156 \\
0.08 & 0.043 & 0.058 & 0.074 & 0.091 & 0.110 & 0.131 & 0.153 \\
0.12 & 0.044 & 0.058 & 0.074 & 0.091 & 0.109 & 0.129 & 0.151 \\
0.16 & 0.045 & 0.059 & 0.074 & 0.091 & 0.109 & 0.128 & 0.149 \\
0.20 & 0.046 & 0.060 & 0.075 & 0.091 & 0.109 & 0.128 & 0.148 \\
0.24 & 0.048 & 0.061 & 0.076 & 0.092 & 0.109 & 0.128 & 0.148 \\
0.28 & 0.049 & 0.062 & 0.077 & 0.092 & 0.109 & 0.128 & 0.147 \\
0.32 & 0.050 & 0.063 & 0.078 & 0.093 & 0.110 & 0.128 & 0.147 \\
0.36 & 0.052 & 0.065 & 0.079 & 0.094 & 0.111 & 0.129 & 0.147 \\
0.40 & 0.053 & 0.066 & 0.080 & 0.096 & 0.112 & 0.129 & 0.148 \\
\hline
\end{tabular}

advancement effect and the production learning effect increase. And $r$ decreases faster with the technological advancement effect. From Table 2 we can also find that although the enhancement of the production learning effect and the technological advancement effect will cause the price discount of the product to fall, when both effects exist simultaneously, and no effect is dominant, the price discount of the product is not monotonous. When $\alpha \in[0.08,0.24]$ and $\beta \in[0.04,0.40]$, the price discount of the product increases first and then decreases as the production learning effect increases.

2) The impacts of $\alpha$ and $\beta$ on $\Delta \pi$

As can be seen from Table 3, the value of the cost reduction $\Delta \pi$ of the firm increases monotonically with the enhancement of the technological advance- 
ment effect. The effect of the production learning effect on $\Delta \pi$ will be influenced by the technological advancement effect. When the technological advancement effect is weak, $\Delta \pi$ increases with the increase of the production learning effect, but when the technological advancement effect is more significant, $\Delta \pi$ increases first and then increases as the production learning effect increases.

On the whole, regardless of the price change of the price discount of the product or the firm's profit change in period 2, their values have a regularity, that is, as the intensity of the $\alpha$ change is significantly greater than the degree of $\beta$ change. This phenomenon also verifies the conclusion of Section 4.1, that the effect of the technological advancement effect on the firm profit is significantly stronger than the effect of the firm the production learning effect. We believe that the possible reason for this result is that the influence of the production learning effect on firm is limited by the sales volume of period 1, and the technological advancement effect has a direct impact on the production cost, so the influence of the technological advancement effect on firm is more significant.

\section{Conclusions}

\subsection{Management Implications}

This paper mainly studies the impact of cost reduction on the value of the price matching, which mainly considers the impact of three factors on the firm pricing, namely the fraction of strategic consumers, the technological advancement effect and the production learning effect. Studies have shown that in the case of a decrease in the cost of period 2, the firm optimal profit decreases with the increase of the fraction of strategic consumers, and the fraction of strategic consumers not only directly affects the price of firm, but also affects the technological advancement and the effect of production learning, indirectly affects firm pricing decisions and profits. The firm's optimal profit increases as the technological advancement effect and the production learning effect increase.

The study also found that firm's phased pricing decision was influenced by the technological advancement effect and the production learning effect. When the production learning effect was more significant (or the technological advancement effect is weaker), firm sold the product at two periods. When the technological advancement effect is significant (or the production learning effect weaker), the firm maintains a uniform price for sale throughout the sales period.

The effect of the fraction of strategic consumers, the technological advancement effect, and the production learning effect on the price discount of the product and the firm the value of the cost reduction is also considered. When the technological advancement effect is dominant, the product is not sold in segments, and the price discount of the product is 1 , that is, the price remains unchanged. The firm's optimal profit increases as the technological advancement effect increases. 
When the production learning effect dominates, the price discount of the product increases as the fraction of strategic consumers increases. When the production learning effect (the technological advancement effect) is more significant, the price discount of the product decreases as the production learning effect (the technological advancement effect) increases, and the firm the value of the cost reduction along with the production learning the effect (the technological advancement effect) increases. And overall, the price and profit of firm are more sensitive to the technological advancement effect.

Based on the above conclusions, firms need to combine the specific characteristics of the products sold by firm when deciding whether to sell in different periods and how to price. For the firm with the obvious advancement effect, under the premise of price reduction of period 2, the firm profit can be maximized by the price combination of period 1 high price and period 2 low price (significantly lower than period 1 pricing). The production learning effect is more obvious, and the firm profit can be maximized by the price combination of period 1 low price and period 2 high price (slightly lower than the price of period 1 ).

In addition, there is no doubt that lowering the cost of the firm can greatly increase the total profit of the firm. Therefore, we also recommend that firm actively seek ways to reduce costs, such as the significant advancement of the technological advancement effect, and the development of new technologies to optimize production and processing. For the significant improvement of the production learning effect, it is possible to optimize the production and processing links, train the production and processing staff, increase the proficiency, thereby improving work efficiency and effectively reducing costs.

\subsection{Research Limitations and Prospects}

The limitations of this paper are as follows. Firstly, we only consider the price matching strategy, and do not consider the other two common pricing strategies, price commitment and dynamic pricing strategy. Secondly, we don't consider the situation of insufficient stocks, when there is a risk of out of stock, consumer decisions will be affected. Lastly, we don't consider the impact of consumer heterogeneity on firm pricing.

Possible future research directions: consider the best pricing strategy choices for firm when there is a shortage of stocks, and consider the pricing strategy choices for firm when there are heterogeneous consumers in the market.

\section{Acknowledgements}

We are grateful to Hua Wang for valuable comments to improve our early version of the study and for motivations of the current version. The research is supported by the Nation Natural Science Foundation of China (71572154), and the Fundamental Research Funds for the Central Universities (26816WTD25). The authors greatly acknowledge the review team for their detailed and constructive comments and advices which helped significantly improve this paper. 


\section{Conflicts of Interest}

The authors declare no conflicts of interest regarding the publication of this paper.

\section{References}

[1] Shum, S., Tong, S. and Xiao, T. (2017) On the Impact of Uncertain Cost Reduction When Selling to Strategic Customers. Management Science, 63, 843-860. https://doi.org/10.1287/mnsc.2015.2355

[2] Alchian, A. (1963) Reliability of Progress Curves in Airframe Production. Econometrica, 31, 679-693. https://doi.org/10.2307/1909166

[3] Benkard, C.L. (2000) Learning and Forgetting: The Dynamics of Aircraft Production. The American Economic Review, 90, 1034-1054. https://doi.org/10.1257/aer.90.4.1034

[4] Guan, Z. and Ren, J. (2014) Dynamic Pricing Strategy for Strategic Consumers. Systems Engineering-Theory and Practice, 34, 2018-2024.

[5] Su, X. (2007) Intertemporal Pricing with Strategic Customer Behavior. Management Science, 53, 726-741. https://doi.org/10.1287/mnsc.1060.0667

[6] Liu, Q. and van Ryzin, G. (2008) Strategic Capacity Rationing to Induce Early Purchases. Management Science, 54, 1115-1131. https://doi.org/10.1287/mnsc.1070.0832

[7] Yin, R., Aviv, Y., Pazgal, A. and Tang, C.S. (2009) Optimal Markdown Pricing: Implications of Inventory Display Formats in the Presence of Strategic Customers. Management Science, 55, 1391-1408. https://doi.org/10.1287/mnsc.1090.1029

[8] Chen, W., Xu, X. and Peng, H. (2015) Product Quality Design and Rapid Response-Based on the Comparison between Short-Sighted Consumers and Strategic Consumers. Journal of Management Sciences in China, 18, 31-38.

[9] Wang, Y., Zhang, J., Cheng, T.C.E. and Hua, G. (2018) Quick Response under Strategic Consumers with Risk Preference and Decreasing Valuation. International Journal of Production Research, 56, 1-14. https://doi.org/10.1080/00207543.2017.1391421

[10] Osadchiy, N. and Vulcano, G. (2010) Selling with Binding Reservations in the Presence of Strategic Consumers. Management Science, 56, 2173-2190. https://doi.org/10.1287/mnsc.1100.1245

[11] Wei, M. and Zhang, F. (2018) Advance Selling to Strategic Consumers: Preorder Contingent Production Strategy with Advance Selling Target. Production and Operations Management, 27, 1221-1235. https://doi.org/10.1111/poms.12863

[12] Su, X. and Zhang, F. (2009) On the Value of Commitment and Availability Guarantees when Selling to Strategic Consumers. Management Science, 55, 713-726. https://doi.org/10.1287/mnsc.1080.0991

[13] Özer, Ö. and Zheng, Y. (2015) Markdown or Everyday-Low-Price? The Role of Behavioral Motives. Management Science, 62, 326-346.

https://doi.org/10.1287/mnsc.2014.2147

[14] Chen, Y., Narasimhan, C. and Zhang, Z. (2001) Consumer Heterogeneity and Competitive Price-Matching Guarantees. Marketing Science, 20, 300-314. https://doi.org/10.1287/mksc.20.3.300.9766

[15] Lai, G.M., Debo, L.G. and Sycara, K. (2010) Buy Now and Match Later: The Impact of Posterior Price Matching on Profit with Strategic Consumers. Manufacturing and 
Service Operations Management, 12, 33-55. https://doi.org/10.1287/msom.1080.0248

[16] Peng, Z., Xiong, Z. and Li, G. (2010) Consider the Dynamic Pricing and Price Return Mechanism of Strategic Customers. Journal of Industrial Engineering and Engineering Management, 24, 53-57.

[17] Dutta, S., Biswas, A. and Grewal, D. (2011) Regret from Postpurchase Discovery of Lower Market Prices: Do Price Refunds Help? Journal of Marketing, 75, 124-138. https://doi.org/10.1509/jm.10.0271

[18] Xing, D. and Liu, T. (2012) Sales Effort Free Riding and Coordination with Price Match and Channel Rebate. European Journal of Operational Research, 219, 264-271. https://doi.org/10.1016/j.ejor.2011.11.029

[19] Tang, X. and Zheng, X. (2017) Pricing of Innovative Product with Cost Information Disclosure and Strategic Consumer Behavior. Chinese Journal of Management, 14, 1538-1545.

[20] Arrow, K.J. (1962) The Economic Implications of Learning by Doing. Review of Economic Studies, 29, 155-173. https://doi.org/10.2307/2295952

[21] Hiller, R.S. and Shapiro, J.F. (1986) Optimal Capacity Expansion Planning When There Are Learning Effects. Management Science, 32, 1153-1163. https://doi.org/10.1287/mnsc.32.9.1153

[22] Hatch, N.W. and Mowery, D.C. (1998) Process Innovation and Learning by Doing in Semiconductor Manufacturing. Management Science, 44, 1461-1477. https://doi.org/10.1287/mnsc.44.11.1461

[23] Cabral, R. and Leiblein, M.J. (2001) Adoption of a Process Innovation with Learning-by-Doing: Evidence from the Semiconductor Industry. Journal of Industrial Economics, 49, 269-280. https://doi.org/10.1111/1467-6451.00149

[24] Kalish, S. (1983) Monopolist Pricing with Dynamic Demand and Production Cost. Marketing Science, 2, 135-159. https://doi.org/10.1287/mksc.2.2.135

[25] Riordan, M.H. (1994) The Learning Curve, Market Dominance, and Predatory Pricing. Econometrica, 62, 1115-1140. https://doi.org/10.2307/2951509

[26] Chen, L., Nan, G. and Li, M. (2018) Wholesale Pricing or Agency Pricing on Online Retail Platforms: The Effects of Customer Loyalty. International Journal of Electronic Commerce, 22, 576-608. https://doi.org/10.1080/10864415.2018.1485086 